\title{
Linguagens e materialidades na arte contemporânea: o lugar da educação infantil e das crianças nesse debate
}

\author{
Languages and materialities in contemporary art: the place of early \\ childhood education and children in this debate
}

\section{Lenguas y materialidades en el arte contemporáneo: el lugar de la educación infantil y de los niños en este debate}

\author{
Lidiane Cristina Loiola Souza' \\ https://orcid.org/0000-0003-4955-7953 \\ Gabriela Guarnieri de Campos Tebet ${ }^{2}$ \\ https://orcid.org/0000-0002-2786-5907
}

\begin{abstract}
Resumo: $O$ objetivo deste texto é discutir os diferentes tipos de relações entre a arte contemporânea, as linguagens e materialidades com as crianças. Para isso mobilizamos conceitos e experiências a partir dos quais discutimos as múltiplas linguagens e materialidades que estão intrínsecas nas experiências das crianças e que dialogam com o modo de ser da arte contemporânea. Para esse debate discutiremos o modo como os termos "diferentes linguagens" e "Múltiplas linguagens" se fazem presentes em documentos oficiais da cidade de São Paulo e do Brasil. Também discutiremos a especificidade e possibilidades que a Arte contemporânea oferece para a educação infantil.
\end{abstract}

Palavras-chave: Educação infantil. Arte contemporânea. Materialidades.

\begin{abstract}
The purpose of this text is to discuss the different types of relationships between contemporary art, languages and materialities with children. For that, we mobilize concepts and experiences from which we discuss the multiple languages and materialities that are intrinsic in the children's experiences and that dialogue with the contemporary art way of being. For this debate we will discuss how the terms "different languages" and "Multiple languages" are present in official curricular documents in the city of São Paulo and Brazil. We will also discuss the specificity and possibilities that contemporary art offers for early childhood education.
\end{abstract}

Keywords: Early childhood education. Contemporary art. Materialities.

Resumen: El propósito de este texto es discutir los diferentes tipos de relaciones entre el arte contemporáneo, los lenguajes y las materialidades con los niños. Para eso, movilizamos conceptos y vivencias a partir de las cuales discutimos los múltiples lenguajes y materialidades que son intrínsecos a las vivencias de los niños y que dialogan con la forma de ser del arte contemporáneo. Para este debate, discutiremos cómo los términos "diferentes lenguajes " y "Múltiples lenguajes " están presentes en los documentos curriculares oficiales de la ciudad de São

\footnotetext{
' Mestra em Educação. Prefeitura Municipal de São Paulo. E-mail: artelidiane@hotmail.com

${ }^{2}$ Doutora em Educação. Faculdade de Educação da UNICAMP. E-mail: gabigt@unicamp.br
}

Olhar de professor, Ponta Grossa, v. 24, p. I-15, e-17748.073, 2021.

Disponível em <https://revistas2.uepg.br/index.php/olhardeprofessor> 
Linguagens e materialidades na arte contemporânea: o lugar da educação infantil e das crianças nesse debate

Paulo y Brasil. También discutiremos la especificidad y posibilidades que ofrece el arte contemporáneo para la educación infantil.

Palabras clave: Educación de la primera infância. Arte Contemporâneo. Materialidades.

\title{
Arte contemporânea, linguagens e materialidades
}

\begin{abstract}
"Através da Arte, os significados dos objetos que de outro modo seriam opacos, caóticos ou restritos e que despertariam resistência, são esclarecidos e concentrados, e não por sua trabalhosa elaboração no pensamento, não pela fuga para um mundo meramente sensorial, mas pela criação de uma mesma experiência” (Dewey, 2010 p. 256).
\end{abstract}

Ao discutirmos a relação entre as crianças e a criação contemporânea, faz-se importante compreendermos a relação entre a arte contemporânea, as linguagens e materialidades que a compõem. A Arte contemporânea se constitui como uma linguagem no campo das Artes sendo múltipla, multicultural, histórica, aborda as mais diversas tecnologias e rompe com materiais nobres ou tradicionais, carregam olhares e proposições artísticas da atualidade relacionando com a vida cotidiana, social, cultural e rompem assuntos e questões, convidando o espectador as mais diversas interpretações, olhares, significados, coautoria e experiências. Para o filósofo Arthur Danto (2006) ○ contemporâneo tem uma perspectiva de desordem informativa, não existe um limite histórico, ou seja, tudo é permitido. De acordo com Cocchiaralle (2006) a arte contemporânea difundiu-se para além de um campo único e especializado, foi sendo construído pelo modernismo e passou a buscar uma interface dialogando com todas as outras linguagens da arte e, mais, com a própria vida, tornando-se para além disso, uma coisa entremeada por outros temas que não são da própria arte. Nesse sentido envolve múltiplas linguagens e essas são valorizadas pela arte contemporânea que dialogando com as experiências com materialidades diversificadas também possuem um papel importante na educação infantil que busca em seu cotidiano propor as crianças o acesso a uma diversidade de materiais com ações para brincar, criar e relacionar os materiais uns com os outros sem uma linearidade.

Nas Diretrizes Curriculares Nacionais para a Educação Infantil, as múltiplas linguagens são referidas nos objetivos com o termo "diferentes linguagens":

A proposta pedagógica das instituições de educação infantil deve ter como objetivo garantir a criança acesso a processos de apropriação, renovação e articulação de conhecimento e aprendizagem de diferentes linguagens, como o direito à proteção, a saúde, à liberdade, à confiança, ao respeito, a dignidade, a brincadeira, a convivência e interação com as outras crianças (BRASIL, 20I0, p. I8).

Este mesmo documento ainda estabelece em um outro momento que as instituições de educação infantil devem garantir experiências que "favoreçam a imersão das crianças nas diferentes linguagens e o progressivo domínio por elas de vários gêneros e formas de expressão: gestual, verbal,

Olhar de professor, Ponta Grossa, v. 24, p. I-15, e-177488.073, 2021.

Disponível em <https://revistas2.uepg.br/index.php/olhardeprofessor> 
plástica, dramática e musical” (BRASIL, 2010, p. 25). Essa passagem evidencia que o trabalho com as diferentes linguagens na educação infantil, não deve ser restrito a atividades voltadas para o ensino e o desenvolvimento da língua portuguesa, mas situa as linguagens no campo das artes, como forma de expressão mais ampla. Porém, em outra parte do texto das diretrizes, o termo múltiplas linguagens aparece no capítulo em que trata sobre Implementação das Diretrizes pelo Ministério da Educação sobre alguns temas e dentre eles cita "Múltiplas linguagens de meninos e meninas no cotidiano da educação infantil” (BRASIL, 20I0, p. 3I).

O parecer CNE/CEB No: 20/2009 dispõe o que integra o processo de tramitação das Diretrizes Curriculares Nacionais para a Educação Infantil no Conselho Nacional de Educação, também não aparece o termo "múltiplas linguagens" mas sim se refere a essa multiplicidade de saberes construídos pelas crianças a partir do termo "diferentes linguagens" mesmo utilizando da palavra "diferentes" as ideias estão permeadas a trazer um sentido sobre as práticas pedagógicas de forma integral, e vê a criança em sua totalidade. $O$ documento nessa perspectiva, destaca que as práticas pedagógicas:

Devem ocorrer de modo a não fragmentar a criança nas suas possibilidades de viver experiências, na sua compreensão do mundo feita pela totalidade de seus sentidos, no conhecimento que constrói na relação intrínseca entre razão e emoção, expressão corporal e verbal, experimentação prática e elaboração conceitual (CNE/CEB No: 20/2009, p. 9).

O documento ainda destaca que é necessário:

Considerar que as linguagens se inter-relacionam: por exemplo, nas brincadeiras cantadas a criança explora as possibilidades expressivas de seus movimentos ao mesmo tempo em que brinca com as palavras e imita certos personagens. Quando se volta para construir conhecimentos sobre diferentes aspectos do seu entorno, a criança elabora suas capacidades linguísticas e cognitivas envolvidas na explicação, argumentação e outras, ao mesmo tempo em que amplia seus conhecimentos sobre o mundo e registra suas descobertas pelo desenho ou mesmo por formas bem iniciais de registro escrito. Por esse motivo, ao planejar o trabalho, é importante não tomar as linguagens de modo isolado ou disciplinar, mas sim contextualizadas, a serviço de significativas aprendizagens (CNE/CEB N: 20/2009, p.I5).

$\mathrm{Na}$ citação acima, convém destacar o trecho "não tomar as linguagens de modo isolado ou disciplinar, mas sim contextualizadas, a serviço de significativas aprendizagens (CNE/CEB $N^{\circ}$ : 20/2009, p.15). O mesmo explicita a importância de garantir experiências pautadas na vida cotidiana, sem ser algo prescritivo ou desarticulado e fragmentado, mas sim articulando os saberes com o patrimônio cultural e o próprio conhecimento de mundo da criança adentrando o processo criativo delas e nas múltiplas linguagens de forma a produzir significado para elas.

Um outro documento de âmbito municipal, o currículo da Educação Infantil da cidade de São Paulo (2019) ressalta a integralidade dos sujeitos por meio das articulações de diferentes saberes, 
Linguagens e materialidades na arte contemporânea: o lugar da educação infantil e das crianças nesse debate linguagens e conhecimentos quando destaca as vivências e práticas sociais ao conversar, brincar, cantar, desenhar, investigar, pesquisar, presentes nas diferentes culturas.

Encontramos na leitura do Currículo da Cidade: Educação Infantil o termo "Múltiplas linguagens" de forma muito recorrente reafirmando que a multiplicidade e a integralidade nas ações com as crianças são importantes:

\begin{abstract}
Integralidade e inteireza dos sujeitos: compreender os sujeitos como seres humanos, seres integrais, desde o nascimento, significa romper com concepções que não valorizam a complexidade desses sujeitos, que constituem em suas relações sociais diferentes dimensões corpóreas e de linguagens, ou seja, que se expressam em múltiplas linguagens. A inteireza que bebês e crianças possuem é tensionada nas experiências de vida que fazem as separações do corpo e da mente, do brincar e do aprender. É necessário assegurar uma educação que valorize a multidimensionalidade humana e contribua para manter a integralidade dos sujeitos, valorizando sentimentos, pensamentos, palavras, ações em suas relações e conexões entre esses sujeitos e o meio (São Paulo. Currículo da Cidade: Educação Infantil, 2019, p. 34).
\end{abstract}

A centralidade das múltiplas linguagens na educação infantil é destacada por diversos autores. Barbieri (20I2) ressalta que trabalhar na educação infantil com as múltiplas linguagens propicia um mundo de descobertas, invenções, conhecimento e estimula a imaginação. A autora afirma ainda que a imaginação e criatividade das crianças não tem limites, porém, se faz necessário favorecer a exploração e apropriação das múltiplas linguagens. Edwards, Gandini e Formann (1999) destacam que as crianças devem ser "encorajadas a explorar o ambiente e se expressarem através de toda as suas "linguagens" em que se inclui as palavras, os movimentos, desenhos, pinturas, textos, colagens e música (EDWARDS; GANDINI; FORMANN, 1999, p. 21 ), ou seja, sempre valorizando a livre expressão das “cem linguagens da criança” (MALAGUZZI, 1998 apud EDWARDS; GANDINI; FORMAN, 2016).

Malaguzzi (1990) utiliza da metáfora "Cem linguagens" para expressar as infinitas formas de linguagens com e para as crianças, que permitem a elas se expressarem por meio da arte, música, pesquisas. Quando Malaguzzi (1990) cita que existem cem imagens diferentes da criança, ressalta que cada um de nós (adultos) temos uma imagem interior diferente desse sujeito criança. E é essa imagem que orienta a nossa ação diante delas. A forma como falamos, escutamos e observamos as crianças está atrelado as nossas ações pedagógicas cotidianas. A palavra multiplicidade permeia a filosofia Reggiana quando conhecemos sua historicidade que perpassa desde a sua construção (múltiplos materiais, resgate), múltiplas pesquisas (autores e experiências diversas), múltiplas formas do adulto enxergar a criança deixando de ser diretivos nas ações e se tornarem aprendizes junto com as crianças que desenvolvem nesse contexto as múltiplas linguagens. Sendo assim, quando falamos sobre essa multiplicidade, destacamos as múltiplas maneiras que as crianças se expressam, se comunicam e se manifestam sendo elas de múltiplas formas. Edwards, Forman e Gandini (1999, p. 38) traz uma fala pertinente para essa exploração com as materialidades "[...] é importante as crianças exploram e em 
detalhes por um extenso período de tempo. Com isso as explorações, perguntas, coletas, representações, memórias, ideias dão asas para novos conhecimentos.

Nesse sentido, o debate que propomos aqui sobre a relação das crianças com a criação contemporânea e as múltiplas linguagens entrelaça-se com um outro sobre as experiências com a materialidade e as oportunidades expressivas que encontram em seu contexto. $O$ debate sobre a relação entre as crianças, a criatividade e materialidade também contribui para a construção do argumento proposto, uma vez que a relação com a materialidade é outra marca importante da arte contemporânea.

Contudo, esse debate é relativamente novo no campo acadêmico e poucas são as produções nessa interface. Uma pesquisa realizada no Scielo com o buscador "materialidade" em 12 de agosto de 2019 localizou apenas 26 artigos, dos quais, nenhum deles dizia respeito à educação infantil ou às crianças pequenas. Quando cruzamos os termos "materialidade" e "infância" ou "materialidade" e "educação infantil" os resultados foram nulos. Quando buscamos por "materialidade" e "arte", localizamos apenas dois artigos, que não se remetem ao trabalho em contexto de educação formal.

Ao realizar a pesquisa no SCOPUS a partir dos mesmos termos "arte "e "materialidade", encontramos 9 pesquisas, porém nenhuma voltada para a educação infantil ou a pedagogia. Todas têm como referência técnica de material. Há que se ressaltar, contudo, que a pesquisa bibliográfica nas referidas bases de dados não. No caso das propostas para a educação infantil, há uma importância atribuída à relação das crianças com os materiais que não pode ser ignorada. Nas Diretrizes Curriculares Nacionais para a Educação Infantil (Brasil, 2010, p.19-21), tanto no item 7 como no item 8, há destaque para a importância do modo como os materiais são organizados. Os itens em questão apontam que a organização dos materiais devem contribuir para uma educação integral, na qual as dimensões expressivo motora, afetiva, cognitiva, linguística, ética, estética e social podem ser tomadas como um cenário completo do assunto: a) devido ao fato de nem todas as publicações estarem indexadas nessas plataformas, b) devido ao fato da pesquisa ter sido realizada em língua portuguesa, excluindo do universo pesquisado publicações em outros idiomas, ou formatos distintos do artigo científico.

O pensador italiano Luigi Pareyson (200l) aborda a questão da materialidade no campo da Arte, porém sua definição para o termo conversa, o tempo inteiro, em como a criança experimenta, cria e recria com o material. Pareyson (200I) ressalta que separar a materialidade de uma obra de arte se torna impossível, pois ela nasce de uma adoção e triunfa como uma nova matéria sendo formada sendo fundamental para o processo de criação do artista. Afirma ainda sobre a relação do artista com o material durante o processo de criação, que o artista percebe a forma (objeto) e pensa em maneiras para criar outras formas com base em seu conhecimento, abrindo assim para novas possibilidades e 
Linguagens e materialidades na arte contemporânea: o lugar da educação infantil e das crianças nesse debate pensamentos priori “desconhecidos”. Essa reflexão de Pareyson dialoga com as múltiplas linguagens da materialidade e a criança, pois ambos, criança e artista estabelecem uma relação com o material de apropriação na intenção de investigar, experimentar, criar e recriar.

Primeiramente nos remetemos ao termo material que para Pareyson (200I) se define como o objeto ou material físico, visto na sua constituição natural que se forma a obra de arte, o artista olha o material inicialmente com um olhar externo e vai escavando outras experiências em busca de um olhar mais interno e no caso da criança o material também se transforma, reverbera em um olhar além do que o material propõe e resulta em brincadeiras, e as mais diversas possibilidades.

O Currículo de Educação Infantil da Cidade de São Paulo (2019), por exemplo, ressalta a materialidade como sendo:

O termo "materialidade" procura expandir o significado de materiais, que podem ser compreendidos por alguns como aqueles de uso escolar. No campo das materialidades, podemos ter um balão e também um filme, galhos ou areias e um varal de poesia, fitas e tambores. Elementos naturais, culturais, tecnológicos: todos são materialidades (São Paulo, Currículo da cidade: Educação Infantil, 20 I9, p. 36)

Ou ainda:

As materialidades agrupam uma imensa gama de objetos, ferramentas, instrumentos que possibilitam investigar, pensar, inventar, raciocinar. Materialidades significativas são os jogos e os brinquedos, os objetos do cotidiano, os materiais artísticos, científicos e tecnológicos, os materiais de largo alcance como pedaços de madeira, pedaços de cano, cordas, rolhas, entre outros. Quando planejamos as materialidades que vamos disponibilizar aos bebês e crianças, é importante considerar quais experiências projetamos para eles, bem como a diversidade e a quantidade de materiais, garantindo que possam fazer suas escolhas individuais, sem que necessariamente façam as mesmas atividades ao mesmo tempo. (São Paulo, Currículo da cidade: Educação Infantil, 2019, p. 135)

Nessa perspectiva, a materialidade é toda potência da matéria e o que ela provoca na criança e sua exploração que vai além dos materiais usuais que as escolas historicamente propõe (lápis de cor, giz de cera, sulfite, cartolina, etc). $O$ documento afirma a busca, pesquisa e inserção nos fazeres com as crianças de materiais até então ditos "inusitados" como gravetos, pedras, sucatas bem selecionadas, papéis diversos, suportes entre outros. O Currículo da Educação Infantil de São Paulo ainda afirma o quanto a exploração de outras diversidades de materiais nos convida a sair do lugar comum e não nega as experiências significativas e o conhecimento. As experiências com pedaços de cano, gravetos, tecidos e linhas entre outros produzem aprendizagens e sentidos. A materialidade não só carrega informações sobre o material (como ele é em seu cotidiano), mas quais as propriedades ele reverbera para a investigação e exploração da criança como por exemplo, a propriedade, temperatura, as cores, formas e dimensões e isso tudo contribuirá para o diálogo e experiência da criança frente ao material. 
No que se refere à materialidade, palavra está muito atrelada aos fazeres artísticos, o documento destaca que o professor deve permitir aos bebês e crianças o acesso com autonomia e que possam experimentar a diversidade de materialidades que se deslocam de ser apenas lápis de cor e folha de sulfite " importante que possam experimentar giz e carvão para desenhar no chão da escola, fazer tinta colorida aproveitando a casca de beterraba, modelar com barro, papel machê e massa de farinha feita com o grupo. Aprender sobre os processos de produção das coisas desperta a imaginação, o pensamento e a vontade de experimentar e criar" (Currículo da Cidade: Educação Infantil, 2019, p. II0).

Tais perspectivas, como percebemos, se assentam em uma concepção de criança criativa, que participa das práticas sociais como protagonista e não apenas como espectadora ou aprendiz.

\title{
O processo criativo das crianças
}

\begin{abstract}
"Criar significa poder compreender e integrar o compreendido em novo nível de consciência. Significa poder condensar o novo entendimento em termos de linguagem. Significa introduzir novas ordenações, formas [...]" (OSTROWER, I 995 p. 25).
\end{abstract}

Figura I: O bolo vulcão (areia, retalhos de tecidos e pedaços de papelão)

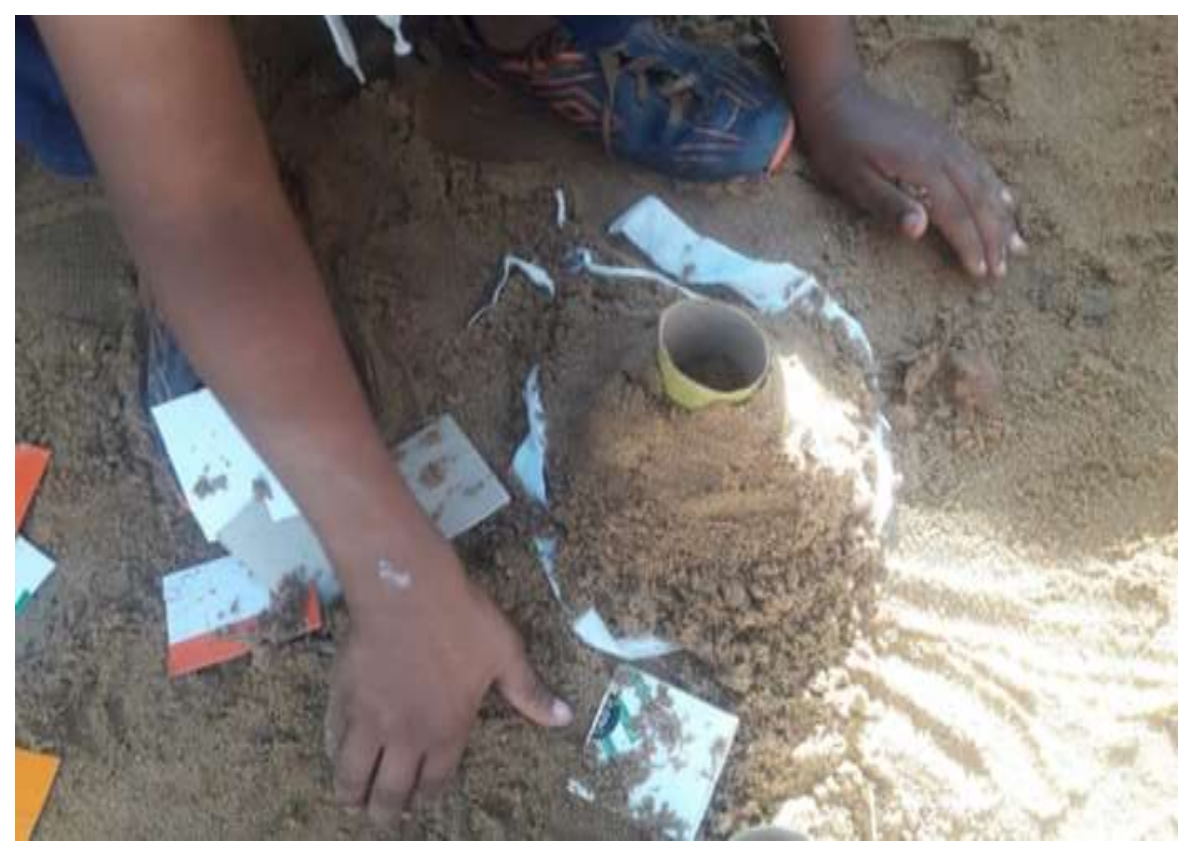

Fonte: Arquivo pessoal, 2018

Ostrower ressalta que a construção criativa está intimamente ligada ao que o sujeito carrega em si e as construções sociais quando destaca 
Linguagens e materialidades na arte contemporânea: o lugar da educação infantil e das crianças nesse debate

A natureza criativa do homem se elabora no contexto cultural. Todo indivíduo se desenvolve em uma realidade social, em cujas necessidades e valorações culturais se moldam nos próprios valores da vida. No indivíduo confrontam-se, por assim dizer, dois polos de uma mesma relação: a sua criatividade que representa potencialidades de um ser único, e sua criação que será a realização destas potencialidades, já dentro de um quadro de uma cultura. (OSTROWER, 1987 p. 5).

A autora afirma que criar não representa uma substituição do real, mas uma intensificação do viver no fazer, trazendo uma realidade nova nas articulações dentro de nós e perante nós. "Daí um sentimento de essencial e do necessário no criar, o sentimento de um crescimento interior em que nós ampliamos em nossa abertura para vida" (OSTROWER, 1995 p. 28).

Nessa ação e experimentação criativa, a criança imagina e gera novas formas com o material e esse objeto da ação não é percebido isolado em si, mas em uma função daquilo que a criança poderia ou desejaria fazer com tais objetos a partir das expectativas e realizações (OSTROWER, 1995).

O criar nas crianças, segundo Ostrower (1995 p. I30), "Está em todo seu modo de viver e agir [...] tudo o que a criança faz, o faz em função da necessidade de seu próprio crescimento da busca de ela se realizar".

Nessa perspectiva, a materialidade é de fato uma das peças chaves para o processo criativo e Fayga Ostrower traz contribuições pertinentes quando ressalta as vivências criativas das crianças que estão intimamente relacionadas à materialidade oferecida a elas. Ressalta que cada materialidade abrange inicialmente certas possibilidades de ação e também carrega as impossibilidades (OSTROWER, 1987).

Com isso, quando nos remetemos à materialidade dentro das múltiplas linguagens, falamos do que podemos ver, perceber e fazer para que a experiência e criação possa existir em um contexto visível e apreciável. Ela dá uma consistência física ao processo de construção. Nesse sentido, as ações criativas não são estáticas mas se movimentam e constroem continuamente quando a criança escolhe, pensar sobre e reconhece e aprecia esses fazeres. E isso se dá na multiplicidade de experiências propostas a elas dando as mesmas a oportunidade de escolha para apoiar e substanciar a criatividade e torná-las autoras.

Quando nos remetemos às experiências, é pertinente um diálogo com Larrosa (2002) que ressalta a arte como um plural de verdades e, acima de tudo, traz um caráter poético. $O$ referido autor (Larrosa, 2002) define a origem da palavra experiência vindo do latim experiri, que significa provar, um encontro com a experimentação, com o arriscar. Ressalta ainda que a experiência possibilita algo que nos aconteça, nos provoque e nos desafie. Nesse sentido, Larrosa (2002, p. 25) argumenta que,

A experiência requer um gesto de interrupção, um gesto que é quase impossível nos tempos que requer parar para pensar, parar para olhar, parar para escutar, pensar mais devagar, olhar mais devagar, e escutar mais devagar; parar para sentir, sentir mais devagar demorar-se nos detalhes, suspender a opinião, suspender o juízo,

Olhar de professor, Ponta Grossa, v. 24, p. I-15, e-17748.073, 2021.

Disponível em <https://revistas2.uepg.br/index.php/olhardeprofessor> 
suspender a vontade, suspender o automatismo da ação, cultivar a atenção e a delicadeza, abrir os olhos e ouvidos, falar sobre o que nos acontece, aprender a lentidão, escutar aos outros, cultivar a arte do encontro, calar muito, ter paciência e dar-se tempo e espaço (LARROSA, 2002, p. 25).

Conforme exposto, o sujeito definido enquanto ação em experiência é convidado a experimentar sem saber se é certo ou errado, e abrir os sentidos para além das possibilidades que convidam à materialidade proposta. A criança tem isso latente, ela se permite acertar ou errar. Assim, a experiência passa a ser compreendida como potencialidade de transformação, sendo aquilo que nos acontece, que nos passa e que, ao tocar, nos transforma continuamente.

Larrosa (2004) afirma que o sujeito de experiência não se define pela atividade, mas acima de tudo em sua passividade, receptividade e disponibilidade pela abertura ao que se propõe. As crianças carregam esse perfil de escutar, de receber e de dispor-se à troca no convívio e na criação imaginativa. Ser receptivo e aberto às ações propostas se torna necessário para promover novas experiências e diante do cenário exposto, pois Larrosa (2002) convida a pensar em uma prática em que haja um olhar diferenciado para a proposição de experiências com as crianças na educação infantil.

Esse olhar nos permite atentar para as potencialidades das crianças, que durante as reflexões buscam entender seus modos de ser e estar no mundo e, com isso, melhor compreender suas ações e experiências. Larrosa (2014) aborda a experiência enquanto relação com o mundo, com a linguagem, os pensamentos e desejos.

Em diálogo com Larrosa, John Dewey (201 I) corrobora com esse contexto quando aborda importantes contribuições para se pensar em um cotidiano que amplie as experiências nas múltiplas linguagens das crianças. É bem certo ressaltar que Dewey não abordou especificamente a infância em seus escritos. Segundo Pinazza (2007) Dewey não esteve preocupado em especial com a infância ou a educação infantil. Ele trata os processos educativos referindo-se à criança individualmente e socialmente e, mesmo não abordando especificamente esse olhar, seus textos nos ajudam e trilhar caminhos potentes para uma pedagogia da infância.

Nesse sentido, consideramos importante abordar as discussões de Dewey nas quais definem experiência como resultado da interação entre o indivíduo e algo do mundo que se vive, uma vez que ressalta que a experiência é uma força em movimento. Para exemplificar o conceito de experiência de Dewey, trouxemos uma metáfora muito recorrente por diversos autores:

Talvez possamos ter uma ilustração geral, se imaginarmos que uma pedra que rola morro abaixo tem uma experiência. Com certeza, trata-se de uma atividade suficientemente "prática". A pedra parte de algum lugar e se move, com a consistência permitida pelas circunstâncias, para um lugar e um estado em que ficará em repouso - em direção a um fim. Acrescentemos a esses dados externos, a guisa da imaginação, a ideia de que a pedra anseia pelo resultado final; de que se interessa pelas coisas 
Linguagens e materialidades na arte contemporânea: o lugar da educação infantil e das crianças nesse debate que encontra no caminho, pelas condições que aceleram e retardam seu avanço, com respeito à influência delas no final; de que age e sente em relação a elas conforme a função de obstáculo ou auxílio que lhes atribui; e de que a chegada final ao repouso se relaciona com tudo o que veio antes, como a culminação de um movimento contínuo. Nesse caso, a pedra teria uma experiência, e uma experiência com qualidade estética. Para Dewey, (2010, p.II5-II6),

Talvez possamos ter uma ilustração geral, se imaginarmos que uma pedra que rola morro abaixo tem uma experiência. Com certeza, trata-se de uma atividade suficientemente "prática". A pedra parte de algum lugar e se move, com a consistência permitida pelas circunstâncias, para um lugar e um estado em que ficará em repouso - em direção a um fim. Acrescentemos a esses dados externos, a guisa da imaginação, a ideia de que a pedra anseia pelo resultado final; de que se interessa pelas coisas que encontra no caminho, pelas condições que aceleram e retardam seu avanço, com respeito à influência delas no final; de que age e sente em relação a elas conforme a função de obstáculo ou auxílio que lhes atribui; e de que a chegada final ao repouso se relaciona com tudo o que veio antes, como a culminação de um movimento contínuo. Nesse caso, a pedra teria uma experiência, e uma experiência com qualidade estética (DEWEY, 2010, p. II5-116).

Nesse paralelo, a criança traz, também, essa força potente de criar imagens e experiências e isso revela um movimento, uma ação sobre si, sobre o outro e sobre as propostas e desafios frente às crianças, preparando para experiências posteriores, aliando, aprofundando e fortalecendo novas iniciativas. A criança por si só traz experiências latentes, são dispostas, curiosas, investigativas e isso se desdobra na descoberta de novas aprendizagens quando vem ao encontro dos objetos e/ou materiais propostos pelo professor.

Assim, a experiência, segundo a perspectiva de Dewey (20II), convida à reflexão, promovendo continuidade, troca de forma a provocar transformações no ambiente e também no próprio sujeito. Dewey (1959) ressalta as experiências nas relações com objetos ou com o outro e o que esse material nos provoca, nos move e nos afeta.

O diálogo entre as múltiplas linguagens e a criança está ligado ao fazer e ao experimentar a todo instante. É uma ação lúdica movida pela curiosidade da criança. Trago para essa reflexão com Dewey uma contribuição de Richter (20l0) ao tratar essa ação da criança ligada ao não conformismo, e ela encontra, ao praticar, outros modos de conhecer, de fazer e de transformar. Isso torna algo visto como conhecimento que remete à novidade e à prática de ações transformadoras.

Dewey trouxe, em seu livro Arte como experiência (2010), contribuições importantes no que diz respeito à arte e a experiências que ela provoca. Dewey (2010) ressalta que a arte deveria se situar ao lado das experiências comuns da vida, ou seja, estar próxima às coisas da natureza como o solo, o ar, as luzes, as flores. Ele afirma que as coisas esteticamente admiráveis brotam desses lugares. São as relações dos sujeitos com o ambiente, junto aos resultados dessa relação que se constitui em uma experiência estética. E essa relação criança, objeto e espaço envolve todos os sentidos, como destaca 
Dewey (2002), “Existe então uma experiência singular quando o material vivenciado faz o percurso até a sua consecução. Então, e só então, ela é integrada e demarcada pelo fluxo geral da experiência proveniente de outras experiências" (DEWEY, 2010 p. II0)

Nessa perspectiva, Dewey $(2010)$ ressalta que as experiências ocorrem continuamente, pois a interação do ser vivido com as condições ambientais está envolvida nesse processo em que toda experiência é constituída pela interação entre "sujeito" e "objeto", entre um eu e seu mundo Dewey (2010). E as múltiplas linguagens carregam esse olhar quando segundo Dewey (2010) ressignifica os objetos trazendo experiências que convida a outros olhares. E seja qual for o caminho seguido nessa ação, ambos os objetos se mantêm vivos em suas experiências plenas e intensas redesenhando uma nova matéria prima.

\section{Materialidade, múltiplas linguagens e a relação da arte contemporânea com as crianças}

Figura 2: "Prô, estou vendo você bem pequenininha!"

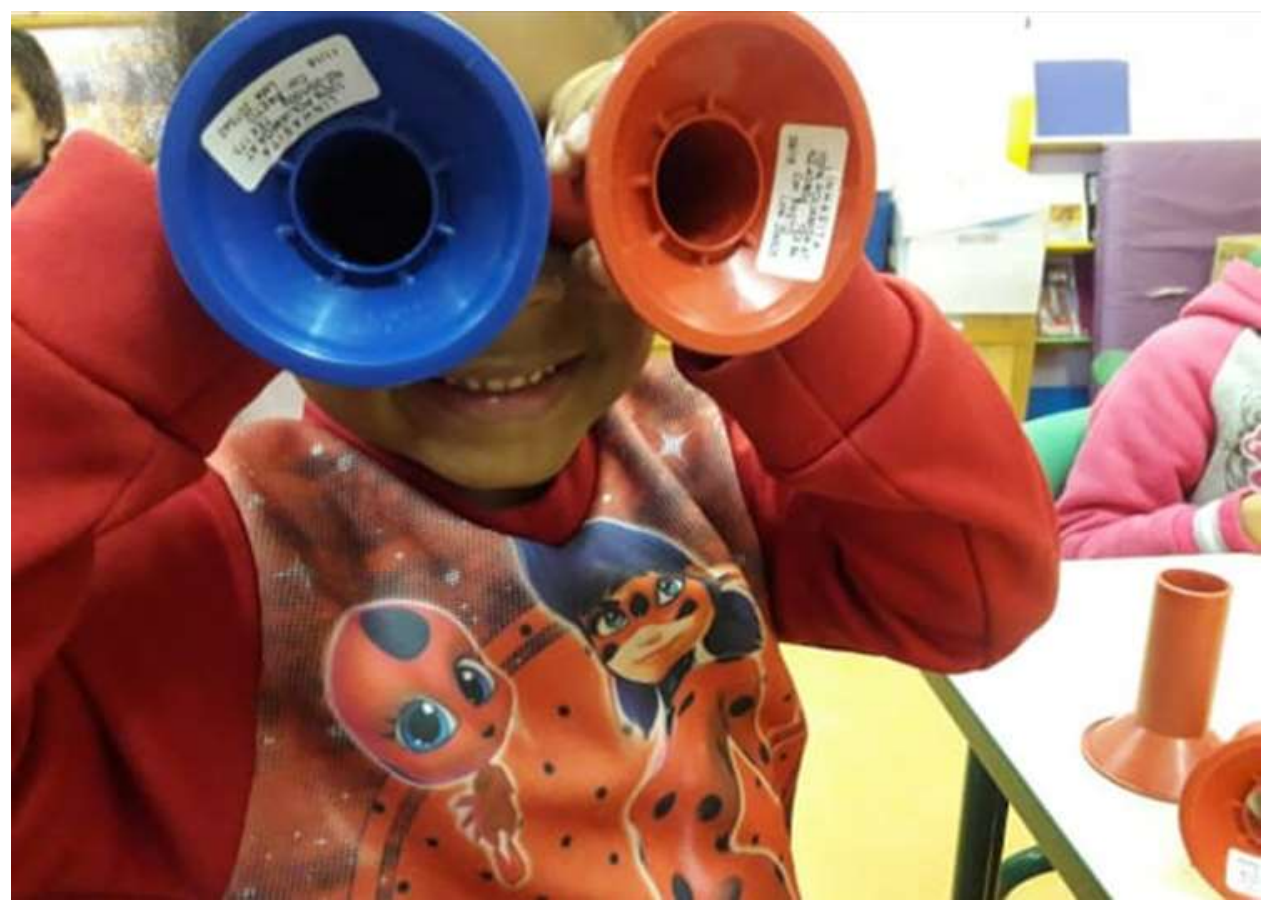

Fonte: Arquivo pessoal,2018

A aproximação das crianças com obras de arte contemporânea dialoga não somente com o olhar, mas também com as múltiplas linguagens e a materialidade que está intrínseca nas experiências. Cunha (2017) ressalta que a arte contemporânea se caracteriza por uma postura dos artistas com ações exploratórias onde as verdades não se findam nelas próprias, mas abrem possibilidades para que o espectador estabeleça novas conexões. Nesse sentido, é importante 
Linguagens e materialidades na arte contemporânea: o lugar da educação infantil e das crianças nesse debate oportunizar às crianças novas experiências e invenções com os materiais dando a elas a possibilidade de interagir, criar e aprender com a arte do seu tempo, ressignificando os objetos dando a eles outros sentidos.

A dimensão criativa, transformativa, é o que nos diferencia das outras espécies, porém isso não quer dizer que todos tenham a possibilidade de desenvolvê-la espontaneamente. As ações pedagógicas precisam ser revisitadas na perspectiva da arte contemporânea em termos dos processos de criação dos artistas, não para copiá-los com "releituras", mas para entender como eles buscam soluções, explorando materiais como os resignificaram e como os apresentaram para os apreciadores dessas obras (CUNHA, 2017, p. 16).

A autora destaca ainda que essa ação não está centrada na obra em si, mas acima de tudo nos pensamentos que podem ser desencadeados a partir da apreciação da arte contemporânea, imaginando, agindo e expandindo a partir das obras.

Corroborando com Cunha, Borges (2013) destaca que a arte contemporânea permite a desconstrução de posturas, questionamentos, conceitos e ideias, (re)significando e dando abertura para o inusitado, para a inquietação, para $\circ$ ato de alimentar o olhar com o que questiona e intriga. Borges (20I3, p.52) afirma que "aproximar as crianças da arte contemporânea é promover" trafegares" descontínuos, deslocamentos e tensionamento". É sair de uma postura mais concreta, para elevar as abstratas, é escavar as obras apresentadas as crianças para um olhar muito além do que os olhos podem enxergar. É sair de uma opinião mais formal ou ainda comum, para posicionamentos amplos e em diálogo com outras narrativas. Não se espera respostas prontas e a sensação do belo, mas provoca e evoca diversas situações, sensações e sentimentos que perpassam para o gostar ou não. A criança, muito mais que o adulto se abre para experiências mais espontâneas por seu diálogo lúdico com o mundo. 
Figura 3: Experiências livre com tecidos

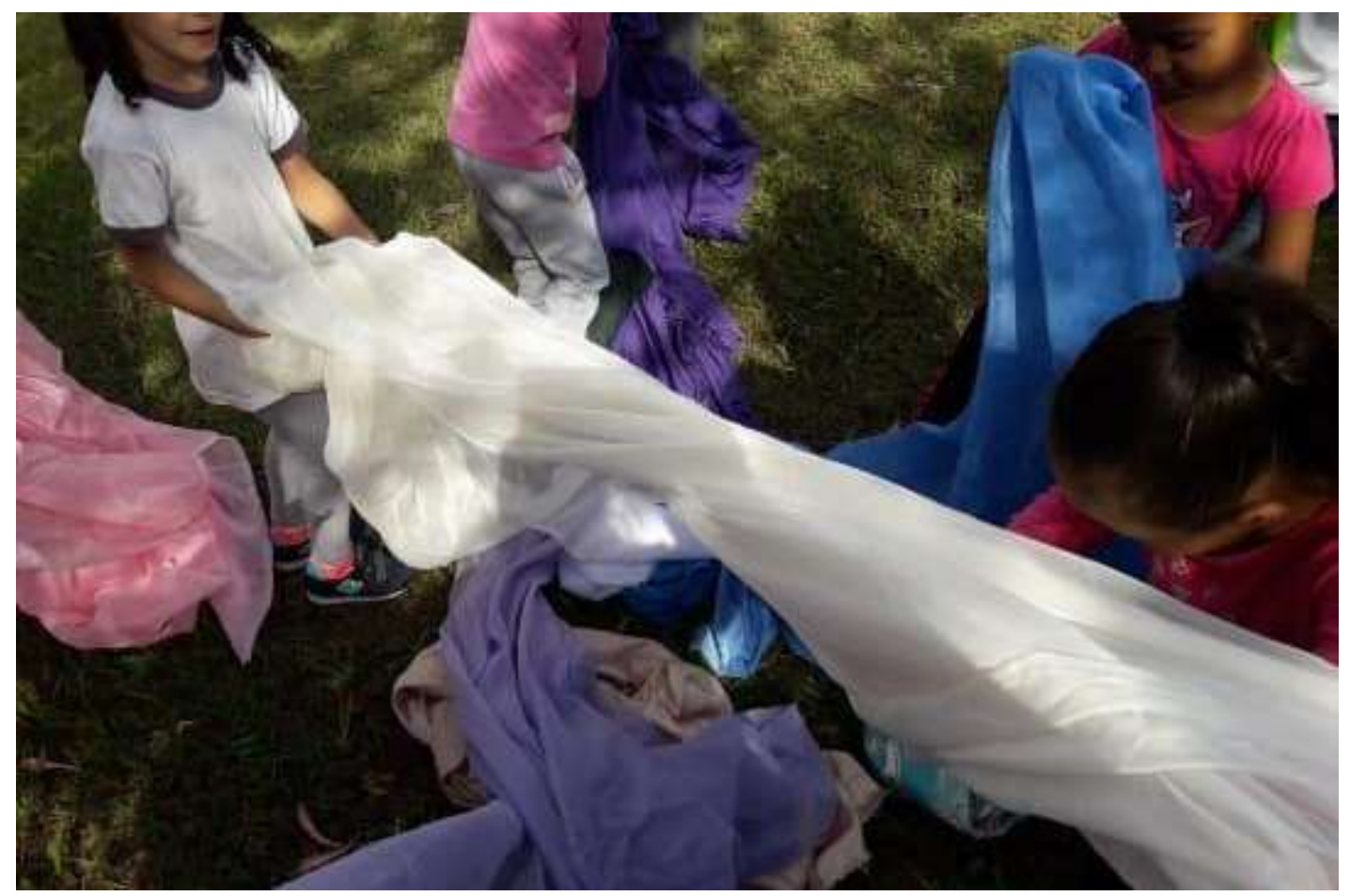

Fonte: Arquivo Pessoal, 2017

Acreditamos que a arte contemporânea se propõe como uma das principais referências enquanto propostas para a educação infantil por trazer em sua concepção o direito de perguntar e responder sem pré julgamentos, por convidar a criança a não só contemplar, mas acima de tudo experimentar, pesquisar e investigar refletindo em outras práticas de seu cotidiano.

A relação da criança com a arte contemporânea pode ser uma das principais referências em proposições pedagógicas para a educação infantil pelo seu cunho não só artístico mas também exploratório e investigativo. Ela convida a criança a dialogar, interrogar e acima de tudo participar não só com falas e pensamentos, mas também com ações. Uma pedagogia em que se insere a arte contemporânea em sua prática dá a oportunidade da criança se expressar e isso eleva a toda sua formação seja ela física, emocional e social.

\section{Referências}

BARBIERI, S. Interações: Onde está a Arte na Infância. São Paulo: Blucher, 2012.

BORGES, C. B. Por entre os dedos: Arte e Crianças Contemporâneas. Dissertação

(Mestrado) Universidade Federal do Rio Grande do Sul. Faculdade de Educação. Programa de PósGraduação em Educação. Porto Alegre, 2013. 
Linguagens e materialidades na arte contemporânea: o lugar da educação infantil e das crianças nesse debate

BRASIL. Ministério da Educação. Parecer CNE/CEB n. 20/2009, de II de novembro de 2009.

BRASIL. Ministério da Educação. Secretaria de Educação Básica. Diretrizes curriculares nacionais para a educação infantil / Secretaria de Educação Básica. - Brasília: MEC, SEB, 20I0. Disponível em: ttp://www.siteal.iipe.unesco.org/sites/default/files/bra-_educacion_infantil.pdf. Acesso em: 10 set. 2019.

COCCHIARALE, F. Rumos da Nova Arte Contemporânea Brasileira. Programa Rumos, Itaú Cultural artes visuais 200I/2003. Janeiro 2002.

CUNHA, S. R. V. da. Uma arte de nosso tempo para as crianças de hoje. In: CUNHA, S. R. V. da; CARVALHO, R. S. de (Org,) A Arte Contemporânea e Educação Infantil. Porto Alegre: Mediação, 2017.

DANTO, A. C. Após o fim da arte: arte contemporânea e os limites da história. São Paulo: Odysseus Editora, 2006.

DEWEY, J. Democracia e Educação. São Paulo: Companhia Editora Nacional, 1959.

DEWEY, J. John Dewey e o ensino de arte no Brasil. São Paulo: Cortez, 2002.

DEWEY, J. A arte como experiência. Trad. Vera Ribeiro. São Paulo: Editora Martins, 2010.

EDWARDS, C. GANDINI, L. FORMAN, G. As cem linguagens da criança: a abordagem de Reggio Emilia na educação da primeira infância. Porto Alegre: Artmed, 1999.

HOYUELOS, A. La ética en el pensamiento y obra pedagógica de Loris Malaguzzi. Barcelona: Octaedro, 2004.

LARROSA, J. Notas sobre a experiência e o saber de experiência. Rev. Bras. de Educação. 2002, n. 19, p. 20-29.

LARROSA, J. Aprender de ouvido. In: Linguagem e educação depois de Babel (trad. FARINA, C.). Belo Horizonte: Autêntica, 2004

LARROSA, J. Pedagogia Profana: Danças, Piruetas e Mascaradas. Tradução: Alfredo Veiga-Neto. 5. ed. Belo Horizonte: Autêntica, 20I4

MALAGUZZI, L. History, ideas and basic philosophy: an interview with Lella Gandiniby Loris Malaguzzi. In: EDWARDS, C.; GANDINI, L.; FORMAN, J. (Ed.). Thehundred languages of children: the Reggio Emilia approach - advanced reflections.London: Ablex Publishing, 1998.

MALAGUZZI, L. Your image of the child: where teaching begins. Child Carelnformation Exchange, Redmond, n. 96, 1994. Disponível em:

<https://static l.squarespace.com/static/56e06e lab654f926bbf666b4/t/56feb83d I d07c087992d0430/I4

59533886240/Your+Image+of+the+Child_+Where+Teaching+Begins.pdf $>$ Acesso em: 24 out. 2019.

OSTROWER, F Universos da arte. Rio de Janeiro: Campus, 1987.

OSTROWER, F. Acasos e criação artística. Rio de Janeiro: Campus, 1995.

PAREYSON, L. Os problemas da estética. 3. ed. São Paulo: Martins Fontes, $200 \mathrm{I}$

Olhar de professor, Ponta Grossa, v. 24, p. I-15, e-177488.073, 2021.

Disponível em <https://revistas2.uepg.br/index.php/olhardeprofessor> 
PINAZZA, M. A. John Dewey: inspirações para uma pedagogia da infância. In: OLIVEIRA-

FORMOSINHO, J.; KISHIMOTO, T. M.; PINAZZA, M. A. (Org.). Pedagogia(s) da infância:

dialogando com o passado, construindo o futuro. Porto Alegre: Artmed, 2007. p. 65-94.

RICHTER, I. M. Multiculturalidade e interdisciplinaridade. In: BARBOSA, Ana Mae (Org.).

Inquietações e mudanças no ensino da arte. 6. ed. São Paulo: Cortez, 20 I0. p. 85-95.

SÃO PAULO (Município). Secretaria Municipal de Educação. Coordenadoria Pedagógica. Currículo da Cidade: Educação Infantil. São Paulo: SME/COPED, 2019.

Recebido em: 06 de abril de 2021 .

Versão corrigida recebida em: 07 de abril de 202I.

Aceito em: II de abril de 202I.

Publicado online em: 17 de julho de 2021 .

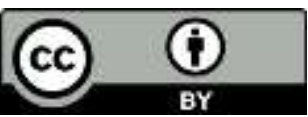

